\title{
Population dynamics of the reef-building coral Acropora hemprichii as an indicator of reef condition
}

\author{
B. Guzner ${ }^{1,2,5, *}$, A. Novoplansky ${ }^{1}$, N. E. Chadwick ${ }^{2,3,4}$ \\ ${ }^{1}$ Mitrani Department of Desert Ecology, Jacob Blaustein Institutes for Desert Research, Ben-Gurion University of the Negev, \\ Midreshet Ben Gurion 8990, Israel \\ ${ }^{2}$ Interuniversity Institute for Marine Science, PO Box 469, Eilat, Israel \\ ${ }^{3}$ Faculty of Life Sciences, Bar Ilan University, Ramat Gan 52900, Israel \\ ${ }^{4}$ Department of Biological Sciences, Auburn University, Auburn, Alabama 36849, USA \\ ${ }^{5}$ Present address: Environmental Sciences and Energy Research Department, Weizman Institute of Science, Rehovot 76100, Israel
}

\begin{abstract}
Population dynamics of stony corals may reveal processes of change in the community structure of coral reefs, yet little information is available on species-specific patterns of recruitment, growth, and mortality in reef corals. We report here on population dynamics of the common reefbuilding coral Acropora hemprichi on a fringing reef slope in the northern Red Sea. Fusion, fission, and partial mortality of colonies were rare in this population. Analysis of population size structure and colony growth and mortality rates revealed a maximum colony age of 13 to 24 yr and rapid population turnover of 10 to $20 \mathrm{yr}$. A deficiency of juveniles resulted in older, larger, and less abundant coral colonies than expected for a population with stable age structure. Colonies of this major reefbuilder appeared to be aging without sufficient replacement, leading to a decline in abundance. Several processes may have contributed to the patterns observed, including variable recruitment over space and time, long-term recruitment failure, and/or low adult mortality. Total percent cover, which was determined mainly by large colonies, was little affected by the paucity of juveniles. We conclude that monitoring of live coral percent cover, even at high taxonomic resolution, cannot detect rapid change in coral assemblages, because it is not sensitive to variation in juvenile abundance and population dynamics. More extensive information on demographic processes, especially species-specific coral recruitment, is urgently needed for the effective and timely management of coral reefs.
\end{abstract}

KEY WORDS: Reef $\cdot$ Coral $\cdot$ Acropora hemprichii $\cdot$ Age $\cdot$ Recruitment $\cdot$ Growth $\cdot$ Mortality $\cdot$ Survival Resale or republication not permitted without written consent of the publisher

\section{INTRODUCTION}

Demographic analysis of coral populations may reveal the extent to which they are under stress (Bak \& Meesters 1999), and is especially useful when anthropogenic activities disturb reefs and threaten the viability of coral populations (Grigg 1984, Smith et al. 2005). Despite their importance, studies that quantify life-history parameters of reef-building corals are few, due, in part, to the difficulties involved in the sampling and aging of coral populations in the field (Grigg 1975). Estimation of coral colony age may involve destructive measurements and be accurate for only certain life forms such as massive (Babcock 1991), free-living (Chadwick-Furman et al. 2000), or solitary corals (Goffredo et al. 2004). In some coral species, growth rate varies widely among individuals, and complex life histories that include fission, fusion, and shrinkage (i.e. partial tissue mortality and skeletal fracture) result in the decoupling of size and age (Hughes \& Jackson 1980, 1985, Hughes 1984, Babcock 1991). Moreover, size may be a more important demographic characteristic than age in terms of growth, mortality, and colony fate, since these processes often are size dependent 
(Hughes \& Connell 1987). Size-frequency distributions of coral populations are a useful tool for assessing the status of coral reefs, since they can reveal variation in patterns of juvenile input, partial mortality, and longevity among coral species, and among populations of a single species over space and time (Bak \& Meesters 1998, 1999, Vermeij \& Bak 2000, Glassom \& Chadwick 2006).

In the Red Sea, the branching stony coral Acropora hemprichii is a major reef-builder that dominates shallow reef slopes (Loya \& Slobodkin 1971, Sheppard \& Sheppard 1991, Rinkevich et al. 1994). Populations of A. hemprichii may serve as indicators of reef condition, since their abundance and percent cover correlate with levels of stony coral percent cover on reefs throughout the northern Gulf of Aqaba, Red Sea (B. Guzner \& N. E. Chadwick unpubl. data). In addition, colonies of A. hemprichii are small and compact, with an upright branching form (Sheppard \& Sheppard 1991), and thus are good candidates for the application of age-based coral population models (ChadwickFurman et al. 2000, Goffredo et al. 2004).

In the present study, we describe patterns of growth and population dynamics in colonies of Acropora hemprichii on a coral reef in the northern Red Sea, and discuss the implications for coral reef monitoring and management.

\section{MATERIALS AND METHODS}

Colony shape. In May 2003, we haphazardly selected 61 undamaged colonies of Acropora hemprichii each $>7 \mathrm{~cm}$ length on artificial substrate at 8 to $15 \mathrm{~m}$ depth at the Eilat Oil and Military Ports (Fig. 1). The colonies were collected using a hammer and chisel and transported to the nearby Interuniversity Institute for Marine Science (IUI, Fig. 1), where they were placed in outdoor aquaria supplied with flowing seawater. Their buoyant weights in seawater (Jokiel et al. 1978) were determined using an electronic balance $( \pm 1 \mathrm{~g}$; Universal Weight Enterprise). Then the length, width, and height of each colony were measured with a set of calipers to an accuracy of $\pm 1 \mathrm{~cm}$, and the geometric mean radius $\left.[\text { GMR }=1 / 2 \text { (length } \times \text { width } \times \text { height })^{1 / 3}\right]$ of each was calculated (Loya 1976) to determine the relationship between GMR and buoyant weight. The following day, all 61 colonies were transplanted to the reef slope adjacent to the IUI at $10 \mathrm{~m}$ depth by attaching them to stainless steel frames positioned $0.5 \mathrm{~m}$ above the substrate to reduce sedimentation on the corals.

In September 2003, the 43 surviving corals were photographed to quantify colony shape, and then were collected and reweighed using the above methods. Each coral was placed on an underwater tripod posi-

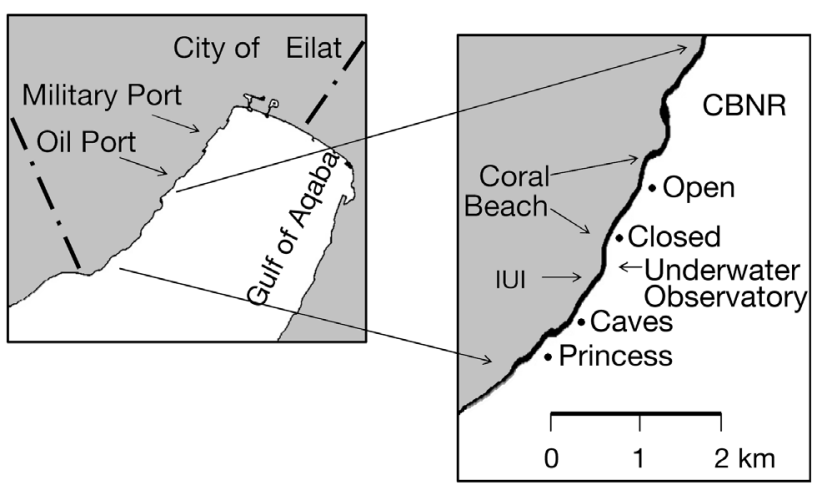

Fig. 1. Study sites at Eilat, northern Red Sea. Scale is shown for inset map of the Coral Beach Nature Reserve (CBNR) (IUI: Interuniversity Institute for Marine Science). Relationships between the linear dimensions and weight of colonies of Acropora hemprichii were determined from corals collected from artificial substrates at the Military and Oil Ports. Growth rates were assessed from naturally occurring colonies at 4 coral reef sites: Open, Closed, Caves, and Princess. Population size structure was examined at the Closed site. The Closed site has also previously been termed the reservation area (Loya \& Slobodkin 1971), nature reserve (Loya 1972, 2004), and Japanese Gardens (Chadwick-Furman et al. 2000)

tioned on the reef slope, and photographed from above and from 4 lateral sides to assess relationships between colony length, width, height, and upper surface area. The photographs were analyzed using Image Tool software (University of Texas Health Science Center in San Antonio, USA).

Colony growth. In July 2003, 20 undamaged colonies of Acropora hemprichii, each 10 to $40 \mathrm{~cm}$ in length, were haphazardly selected and marked at 5 to $10 \mathrm{~m}$ depth on the reef slope at each of 4 sites in the Coral Beach Nature Reserve of Eilat: Open, Closed, Caves, and Princess (80 colonies in all, Fig. 1). A photograph including a scale bar was taken of each colony from above, and colony height was measured manually. In July 2004, the colonies were rephotographed and measured. Laminated photographs from 2003 were used to assure that the second set of photographs was taken from the same angle. The length and width of each coral from the photographs were analyzed using the above software. GMR was calculated from the dimensions of each colony, and used to estimate buoyant weight based on the relationship between GMR and buoyant weight from transplanted corals, as described above. The change in estimated buoyant weight over $1 \mathrm{yr}$ was used as a measure of growth. To model how coral weight $(w)$ changed with age $(t)$, a linear equation in the form of $\mathrm{d} w / \mathrm{d} t=a w+b$ was fitted to the growth data, where $a$ is the regression slope and $b$ is the intercept. The residuals of the regression were tested for normality, constancy of variance, and 
correlations between residuals. The integrated form of this equation was $w_{t}=(b / a)\left(\mathrm{e}^{a t}-1\right)$, where $w_{t}$ is the weight (in $\mathrm{g}$ ) at age $t(\mathrm{yr})$ and $t$ is age in years (after Grigg 1974, 1984). We assumed that all sampled corals followed the same growth trajectory. We thus describe the average performance of individuals of different sizes under a more or less similar set of conditions (Kaufmann 1981). The few corals that suffered skeletal fracture and/or partial tissue mortality during the study year were excluded from growth estimates, so rates reported here reflect maximal growth for colonies in each size class (after Chadwick-Furman et al. 2000).

Population size and age structure. In July 2003, eight $1 \times 10 \mathrm{~m}$ belt transects were deployed haphazardly at 5 to $10 \mathrm{~m}$ depth on the reef slope at the Closed site (Fig. 1), and the linear dimensions (length, width, height) of all colonies of Acropora hemprichii inside the transects were measured. The reef substratum was searched carefully to detect small individuals (after Glassom \& Chadwick 2006). The GMR of each colony was calculated and converted to buoyant weight as described above. Data were pooled from the 8 transects to obtain enough corals for population analysis ( $N=131$ corals in total, after Smith et al. 2005). Population age structure was obtained by estimating the age of each colony from its size based on the above growth function, then segregating the corals into age classes.

Colony fates. In July 2003, we marked and photographed 61 haphazardly selected undamaged individuals of Acropora hemprichii each 10 to $40 \mathrm{~cm}$ in length at 5 to $10 \mathrm{~m}$ depth at the Closed site (Fig. 1). These colonies were different from those photographed for assessment of growth rates above. In July 2004, the photographs were retaken and analyzed as described above to determine the percent of colonies that had undergone fission, fusion, and complete and partial tissue mortality.

Colony abundance and percent cover. The abundance of colonies of Acropora hemprichii was determined inside the above belt transects that were examined for population structure $\left(\mathrm{N}=8\right.$ transects of $10 \mathrm{~m}^{2}$ each). The percent area covered by colonies of $A$. hemprichii and their contribution to total live coral cover were estimated by randomly placing 20 quadrats of $1 \mathrm{~m}^{2}$ along a $50 \mathrm{~m}$ line transect deployed at $5 \mathrm{~m}$ depth parallel to the shore at the Closed site (Fig. 1). We randomly assigned 10 sampling points within each quadrat, and recorded the number of points that were located above live stony corals, live branching stony corals, and colonies of $A$. hemprichii.

All results are presented as means \pm 1 SD unless otherwise indicated. Statistical analyses were conducted using Statistica Version 7.1 (StatSoft). Confidence interval estimates for population parameters were calculated from Ebert (1999).

\section{RESULTS}

\section{Colony shape}

In colonies of Acropora hemprichii, buoyant weight and upper surface area both increased exponentially with GMR (Fig. 2a,b). The relationship between upper surface area and buoyant weight was linear (Fig. 2c). Colony height increased with buoyant weight up to about $200 \mathrm{~g}$, then leveled off, indicating that the corals reached a height asymptote above this weight (Fig. 2d). The height to width ratio of small corals was close to 1, indicating a roughly spherical colony form, then rapidly decreased as colonies became much wider than they were tall, and developed a flat table shape (Fig. 2e). The corals had a length to width ratio of $0.82 \pm 0.13$, forming a slightly oblong outline when viewed from above (Fig. 2f).

\section{Colony growth}

Coral growth rates did not vary significantly among the 4 sites examined (Fig. 1, 1-way ANOVA, df = 3,51, $F=0.77, \mathrm{p}>0.51$ ), so growth data were pooled from all sites. Absolute growth over 1 yr varied widely among individuals and increased significantly with initial coral size, indicating that colonies of Acropora hemprichii increased their rates of growth in weight as they became larger (Fig. 3a). These rates of growth in weight corresponded to annual skeletal extension rates in colony length of $2.55 \pm 1.35 \mathrm{~cm} \mathrm{yr}^{-1}(\mathrm{~N}=54$ colonies).

A growth function that described a linear increase in annual weight gain with initial coral weight fitted the data better $(r=0.626, p<0.001$; Fig. 3a) than did curvilinear growth functions describing either exponential increase $(r=0.525)$ or decrease $(r=0.587)$ in annual growth rate.

Due to the above linear increase in growth rate with size, the corals exponentially increased their size in weight as they aged (Fig. 3b). The observed variation in growth rates among individuals (Fig. 3a) allowed calculation of $95 \%$ confidence limits for the regression slope and intercept of the growth equation (Table 1).

\section{Population size and age structure}

The population consisted mostly of medium-sized and large corals, with relatively few small colonies except in the smallest size class (Fig. 4). The estimated population age structure was dominated by 6 to $11 \mathrm{yr}$ old corals (Fig. 4a). Mean coral age was 8 yr, and mean size was about $520 \mathrm{~g}$ buoyant weight or $8 \mathrm{~cm}$ GMR 

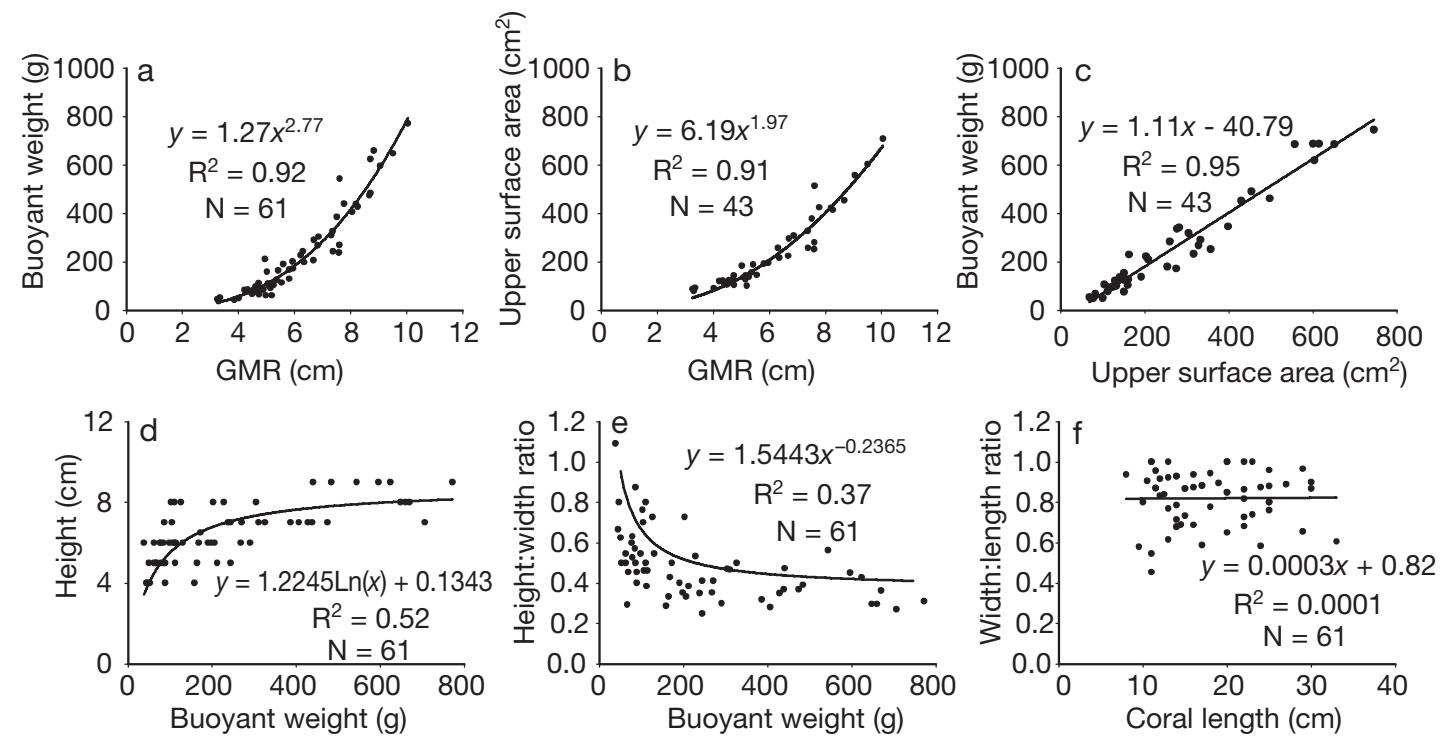

Fig. 2. Acropora hemprichii. Size and shape relationships in colonies at Eilat, northern Red Sea. (a) Exponential increase in buoyant weight with geometric mean radius (GMR). (b) Exponential increase in upper surface area with GMR. (c) Linear increase in buoyant weight with upper surface area. (d) Initial increase in colony height with buoyant weight, then leveling off as corals reach a height asymptote at $>100 \mathrm{~g}$. (e) Reduction in height:width ratio with buoyant weight. (f) Constant length:width ratio with increasing colony length, indicating a slightly oblong colony shape. Data in (a), (d), (e) and (f) are from direct measurements of weights and dimensions on 61 corals that were collected from the Military and Oil Ports in May 2003; data in (b) and (c) are from direct measurements of weights and from photographs of upper colony surface areas on 43 of these corals on the IUI reef in September 2003
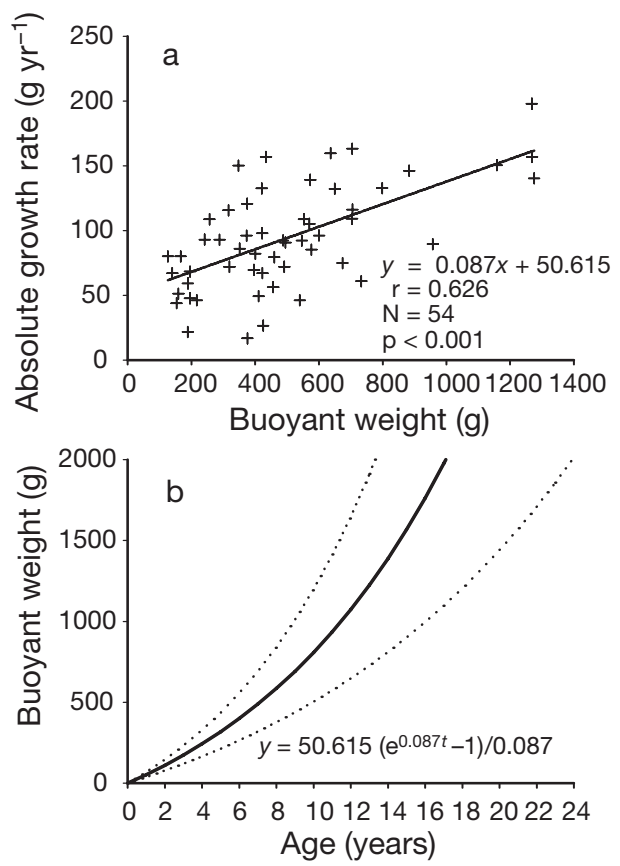

Fig. 3. Acropora hemprichii. (a) Absolute annual growth of naturally occurring colonies at 5 to $10 \mathrm{~m}$ depth on coral reef slopes at Eilat, northern Red Sea. Data are reported for 54 corals out of 80 that were monitored for growth during 2003 and 2004. Some corals were excluded from analysis due to lack of clarity in the photographs and damage to the corals. The weight of each coral was estimated from its geometric mean radius using the equation in Fig. 2a. See 'Materials and methods' for details. (b) Lifetime growth trajectory $\pm 95 \%$ confidence intervals
Table 1. Acropora hemprichii. The 95\% confidence intervals (CI) of the slope and intercept of the growth rate equation given in Fig. 3a, as applied to the lifetime growth trajectory estimated in Fig. 3b

\begin{tabular}{|lcc|}
\hline & Slope $(a)$ & Intercept $(b)$ \\
\hline Value \pm SE & $0.087 \pm 0.016$ & $50.6 \pm 8.7$ \\
$95 \%$ CI & $0.062-0.112$ & $36.3-64.9$ \\
\hline
\end{tabular}

(= $24 \mathrm{~cm}$ length), while maximum coral age was $17 \mathrm{yr}$, and maximum size was about $2000 \mathrm{~g}$ buoyant weight or $14 \mathrm{~cm} \mathrm{GMR} \mathrm{(=56} \mathrm{cm} \mathrm{colony} \mathrm{length)} \mathrm{(Fig.} \mathrm{4a).} \mathrm{The}$ lower $95 \%$ confidence limit for the population age structure based on the error estimate from the growth model (Table 1) indicated a population dominated by 4 to $8 \mathrm{yr}$ old corals, with a maximum age of $13 \mathrm{yr}$ (Fig. 4b), while the upper 95\% confidence limit indicated a population dominated by 15 to 16 yr old corals, with a maximum age of 24 yr (Fig. 4c).

\section{Colony fates}

Fusion, fission, and partial tissue mortality were rare in this population. Of 61 individuals monitored over $1 \mathrm{yr}$, none fused with neighboring colonies. Fission in the form of skeletal fragmentation occurred in 6 colonies $(10.2 \%)$. In only 2 of these (3.3\%), colony vol- 
ume was reduced by $>5 \%$ due to fragment loss. Thus, fragmentation that substantially reduced colony size was estimated to occur in $3.3 \%$ of the population $(\mathrm{N}=$

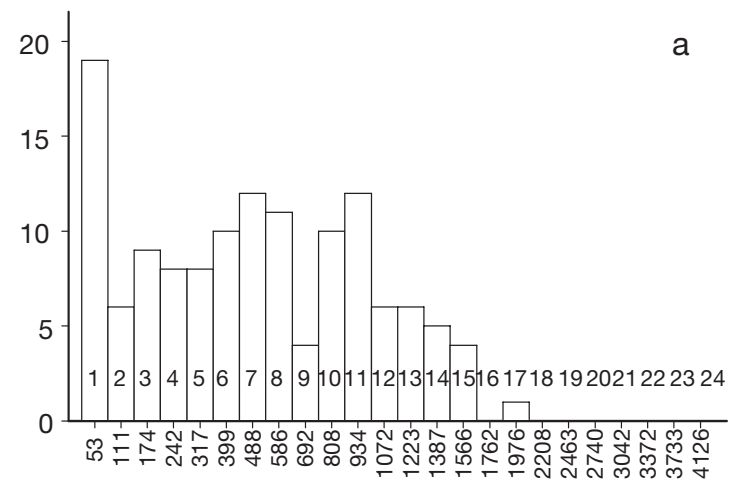
ॠ
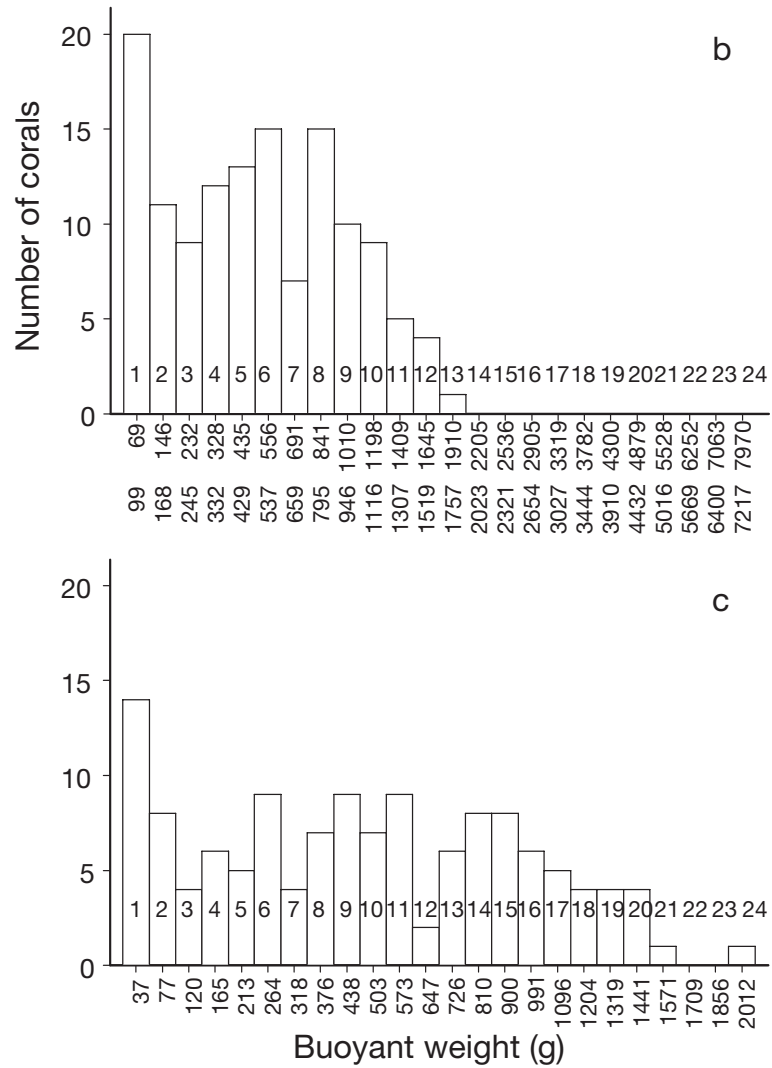

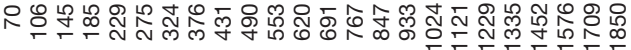
Upper surface area $\left(\mathrm{cm}^{2}\right)$

Fig. 4. Acropora hemprichii. Population age and size distributions at the Closed site, Eilat, northern Red Sea. The geometric mean radii of 131 corals were measured and converted to buoyant weight, upper surface area, and estimated age (in years, shown inside bars) $\pm 95 \%$ confidence intervals, from the relationships in Figs. 2 \& 3. (a) Estimated age and size distributions. (b) Lower $95 \%$ confidence limit of the estimate. (c) Upper $95 \%$ confidence limit of the estimate. Note that maximum coral age ranged from 13 to $24 \mathrm{yr}$
61) during the study year. Lower and upper 95\% confidence limits for the colony fragmentation rate were 0.5 and $9.9 \%$, respectively. None of the detached fragments survived, indicating that clonal input to this population from fission was negligible during the year examined.

Four colonies $(6.5 \%, \mathrm{~N}=61)$ experienced partial tissue mortality in which the skeleton became partly exposed and overgrown by fouling algae. Three of these colonies $(4.9 \%)$ lost over half their tissue, indicating extensive partial mortality, and appeared to be in the process of dying. Three additional colonies $(4.9 \%)$ suffered complete mortality during the study year. Thus, estimated finite annual mortality rate for this population was $4.9 \% \mathrm{yr}^{-1}$ if only completely dead corals were included $(95 \%$ confidence limits of the estimate $=1.2$ to $12.3 \%$ ). If both completely and nearly dead corals were included, then estimated finite annual mortality was $9.8 \% \mathrm{yr}^{-1}$ (95\% confidence limits of the estimate $=4.0$ to $19.9 \%$ ).

Based on the above rates of mortality, this population was estimated to have a turnover rate of 10.2 to $20.4 \mathrm{yr}$, equal to the inverse of the annual mortality rate of 4.9 to $9.8 \% \mathrm{yr}^{-1}$ (after Chadwick-Furman et al. 2000).

\section{Colony abundance and percent cover}

Colonies of Acropora hemprichii occurred at an abundance of $1.5 \pm 0.6$ ind. $\mathrm{m}^{-2}$ on the shallow reef slope at the Closed site ( $\mathrm{N}=8$ transects, $10 \mathrm{~m}^{2}$ each). Their percent cover was $9.0 \pm 13.7 \%$, while the percent cover of branching stony corals was $17.5 \pm 18.0 \%$, and the percent cover of all live stony corals was $34.5 \pm$ $18.9 \%(\mathrm{~N}=20$ quadrats $)$. As such, colonies of $A$. hemprichii contributed more than half the percent cover of branching stony corals, and about $25 \%$ of the total live stony coral cover. Colonies of $A$. hemprichii that were below mean size (dimensions given above) contributed $<30 \%$ to the percent cover of the population (Fig. 5).

\section{DISCUSSION}

In the present study, we show here that colonies of the major reef-builder Acropora hemprichii in the northern Red Sea grow rapidly and live for a short period of only 13 to $24 \mathrm{yr}$, resulting in a highly dynamic population with rapid turnover. A dearth of juvenile recruits indicates a potentially declining population that may be aging without adequate replacement of colonies. The percent live cover of this species is determined mainly by large colonies and thus does not reveal the low relative abundance of juveniles. We 


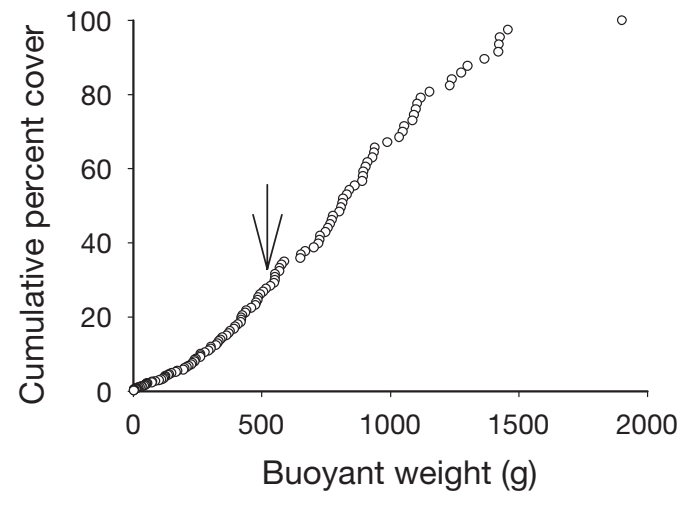

Fig. 5. Acropora hemprichii. Contribution of colonies by size to cumulative percent cover at the Closed site, Eilat, northern Red Sea. Buoyant weights were estimated from the linear dimensions of colonies examined in field transects (see 'Materials and methods' for details). The arrow indicates mean colony weight

predict that, unless juvenile coral recruitment increases in the near future at this site, the population may experience further decline in abundance due to the aging of colonies without sufficient replacement. Our data reveal population processes that may contribute to the observed long-term patterns of decline in the coral community at this site (Loya 2004).

We also document allometric growth for members of this species, in that the colonies change shape as they increase in size. Allometric growth is known for many types of stony corals and usually involves a gradual transformation from a symmetrical (often spherical or circular) growth form to one that is oblong, oval, or table shaped (Bablet 1985, Babcock 1991, ChadwickFurman et al. 2000, Goffredo et al. 2004).

The increasing growth rate in colony weight that we observed for Acropora hemprichii also is known to occur in other corals, including members of both massive (Babcock 1991) and branching species (Grigg 1984, Ross 1984). In contrast, growth rates of some stony corals decrease with age (Rinkevich \& Loya 1986, Goffredo \& Chadwick-Furman 2003). The large variation in growth rate among individuals that we observed is a common feature of scleractinian corals (Babcock 1991, Chadwick-Furman et al. 2000, Goffredo et al. 2004). Growth rates measured for $A$. hemprichii were similar to those previously reported for interacting colonies of this species at Eilat (Rinkevich et al. 1994) and for similar-sized colonies of the congener A. hyacinthus in the Philippines (Yap et al. 1992). However, they were much slower than those known for some fast-growing species of Acropora that can reach lateral extension rates of $>20 \mathrm{~cm} \mathrm{yr}^{-1}$ (Crabbe \& Smith 2005). Colonies of $A$. hemprichii are endemic to the western Indian Ocean and Red Sea (Veron 2000). The present study is the first to measure growth in a natural population of this species, so variation in growth among reef areas is not yet known. We show that the growth rates in weight of field colonies of $A$. hemprichii can be determined accurately from measurement of changes in their upper surface area, due to the strong correlation between surface area and buoyant weight (Fig. 2c).

Several factors limit the interpretation of our growth data. Firstly, the relationships between linear dimensions and colony weight were based entirely on corals from artificial substrate at port facilities. However, our preliminary data indicated that in Acropora hemprichii this relationship does not vary substantially between artificial and natural reef areas at Eilat, so our estimates likely were accurate for the corals we examined on natural reefs. Further, we did not measure growth in very small corals, which limited our ability to determine accurate age-size relationships for corals in the youngest age classes. Our data on coral growth were collected over only $1 \mathrm{yr}$, and so do not reveal interannual variation. Finally, coral growth did not vary spatially among the 4 sites we examined, but these sites all were located within a small area of $3 \mathrm{~km}$ and may not reflect growth at sites further south in the Red Sea, where stony corals are known to grow more rapidly (Chadwick-Furman et al. 2000).

The dominance of the observed population structure by medium-sized corals may indicate population instability. Cohorts of stony corals usually are characterized by exponentially decreasing mortality with time, assuming constant recruitment and mortality rates (Grigg 1975), so coral size distributions tend to be negatively skewed and dominated by small colonies (Hughes \& Jackson 1985, Babcock 1991, Bak \& Meesters 1999, Goffredo et al. 2004, Glassom \& Chadwick 2006). In contrast, our results reveal a potential deficit of juvenile corals, which may be caused by several factors. We may not have detected some very small corals, as known from other studies on coral demography (Grigg 1984, Glassom \& Chadwick 2006). Since we carefully searched the reef substratum within our transects (see 'Materials and methods'), missed corals likely were $<2.5 \mathrm{~cm}$ length $(<1 \mathrm{yr}$ old, see 'Results') and would not have substantially changed the overall age distribution pattern. The pattern of relatively few small corals in our population also may have been caused, in part, by spatio-temporal variation in recruitment. Acroporid corals are broadcast spawners with long-lived and widely dispersing larvae that recruit sporadically, and thus these corals may rarely achieve steady-state even in stable environments (Harriott \& Banks 1995, Glassom et al. 2004). Finally, the examined reef site recently was closed to diving tourism and, thus, currently experiences low levels of mechanical breakage to corals relative to other reef 
sites in the area (Epstein et al. 1999, Zakai \& Chadwick-Furman 2002), possibly leading to enhanced survival of large colonies. This process, together with the low and variable coral recruitment known to occur at Eilat in recent years (Glassom et al. 2004, Abelson et al. 2005, Glassom \& Chadwick 2006), may have led to the unusually high abundance of adults relative to juveniles that we observed in the present study.

None of the observed colonies fused and only few experienced fission or partial tissue mortality, indicating that age and size appear to be correlated for most colonies of this species at our study site. Thus, our estimates of coral age and growth are likely to be fairly accurate for this reef location, given the above caveats. Decoupling between size and age increases with coral size (Grigg 1975; Fig. 3b), so our margins of error for the age distribution were larger for medium to large colonies. However, all 3 age distributions showed a consistently low abundance of small, young corals (Fig. $4 \mathrm{a}-\mathrm{c}$ ). The lack of reproduction by fragmentation in this species also has been noted in past studies at Eilat (Rinkevich et al. 1994).

The annual mortality rates estimated here for Acropora hemprichii (4.9 to $9.8 \% \mathrm{yr}^{-1}$ ) were lower than those determined for solitary mushroom corals at this location (12 to $43 \% \mathrm{yr}^{-1}$, Goffredo \& ChadwickFurman 2003), and for some branching corals at other sites (Pocillopora verrucosa in the Philippines, 34\% [Ross 1984]; Acropora spp. in Australia, 16 to $40 \%$ [Smith et al. 2005]). However, they are within the range of mortality rates estimated for some other tropical and temperate corals (reviewed in ChadwickFurman et al. 2000).

Total percent coral cover has decreased considerably at this site over the past 3 decades $(52.9 \pm 18.1 \%$ at 3 to $7 \mathrm{~m}$ depth [Loya 1972] vs. $34.5 \pm 18.9 \%$ at $5 \mathrm{~m}$ depth [present study]), indicating long-term reef decline (Loya 2004). Colonies of Acropora hemprichii currently also contribute more to the percent cover of live stony corals $(26.1 \%)$ than they did at this site about $30 \mathrm{yr}$ ago (9.5\%; Loya \& Slobodkin 1971), indicating that members of other coral species may have declined more (Loya 2004) than A. hemprichii colonies in recent years. Some branching stony corals have weedy lifehistory strategies relative to other life forms such as massive corals (Loya 1976). Thus, a current trend in reef dynamics at Eilat may be an increasing dominance of the community by branching stony corals with high turnover rates. The relatively low rates of colony mortality observed during the study year indicate that decline in the coral assemblages on local reefs may not be based primarily on adult mortality. The mean size of colonies of $A$. hemprichii at this site has increased substantially over the years (8 to $11 \mathrm{~cm}$ length [Loya 1972] compared to $24 \mathrm{~cm}$ length [present study]), indicating that the population is dominated by larger, older corals than in the past.

We propose that reduced recruitment of juvenile corals may have contributed in large part to decreases in coral abundance on these reefs. Data from other sites at Eilat show that the composition of local coral assemblages are determined mainly by recruitment patterns rather than by post-recruitment mortality or growth (Glassom \& Chadwick 2006). Recent studies at Eilat also have revealed depressed rates of coral sexual reproduction (Glassom et al. 2004, Zakai et al. 2006) and recruitment (Glassom et al. 2004, Abelson et al. 2005). Since seeding larvae of Acropora hemprichii are likely to originate from remote upstream populations, the paucity of young corals observed in the present study may reflect a decrease in coral fecundity over a large spatial scale (Ayre \& Hughes 2000, Hughes \& Tanner 2000, Glassom et al. 2004). Fencing off a small reef area and closing it to diving tourism as has been done for the Closed site at Eilat (Epstein et al. 1999, Zakai \& Chadwick-Furman 2002) may increase adult survival by protecting corals from trampling, but the viability of these populations critically depends on an ongoing supply of larvae from more distant source populations (Caley et al. 1996). Possible recruitment failure in $A$. hemprichii, thus, may indicate a more widespread deterioration of reefs in the northern Red Sea region. Our data highlight the possible importance of connectivity of reefs in this region and the need for an integrated conservation strategy among neighboring countries.

Traditional monitoring of coral percent cover usually cannot detect changes in coral health over short time scales or predict trends of future change on reefs (reviewed in Smith et al. 2005). Since the live percent cover of stony corals depends mostly on colonies in the largest size classes (Hughes \& Jackson 1985, Babcock 1991; Fig. 5), reduced abundance of juveniles due to recruitment failure is not necessarily followed immediately by a sharp decline in live percent cover, which instead will lag by several years. Thus, on reefs with reduced recruitment, such failures will not be detected in a timely fashion by the conventional method of monitoring live coral cover, since this parameter does not reveal the abundance or dynamics of coral colonies in endangered populations. We conclude that more extensive information on demographic processes, especially on species-specific patterns of coral recruitment, is urgently needed for the effective and timely management of coral reefs.

Acknowledgements. We thank the staff of the Interuniversity Institute for Marine Science for administrative and technical support, M. Kiflawi and O. Ovadia for information on model development, B. Rinkevich and D. Saltz for constructive comments 
on early drafts of the manuscript, and A. Genin and I. Ayalon for underwater camera use. Many people assisted in the field work, including K. Tarnaruder, A. Eshel, E. Brokovich, B. Kuguru, O. Shalit, and O. Novoplansky. We also thank the Israel Nature and Parks Authority, especially D. Zakai and E. Dagan, for their support and for issuing a permit to conduct this project. This research is Publication Number 564 of the Mitrani Department of Desert Ecology at Ben Gurion University and Publication Number 21 of the Marine Biology Program at Auburn University. Funding was provided by grants from Bar Ilan University and Auburn University to N.E.C.

\section{LITERATURE CITED}

Abelson A, Olinky R, Gaines S (2005) Coral recruitment to the reefs of Eilat, Red Sea: temporal and spatial variation, and possible effects of anthropogenic disturbances. Mar Pollut Bull 50:576-582

Ayre DJ, Hughes TP (2000) Genotypic diversity and gene flow in brooding and spawning corals along the Great Barrier Reef, Australia. Evolution 54:1590-1605

Babcock RC (1991) Comparative demography of three species of scleractinian corals using age- and size-dependent classifications. Ecol Monogr 61:225-244

Bablet JP (1985) Report on the growth of a Scleractinia (Fungia paumotensis). In: Proc 5th Int Coral Reef Congr, Vol 4. Antenne Museum -EPHE, Moorea, Tahiti, p 361-366

Bak RPM, Meesters EH (1998) Coral population structure: the hidden information of colony size-frequency distributions. Mar Ecol Prog Ser 162:301-306

Bak RPM, Meesters EH (1999) Population structure as a response of coral communities to global change. Am Zool 39:56-65

Caley MJ, Carr MH, Hixon MA, Hughes TP, Jones GP, Menge BA (1996) Recruitment and the local dynamics of open marine populations. Annu Rev Ecol Syst 27:477-500

Chadwick-Furman NE, Goffredo S, Loya Y (2000) Growth and population dynamic model of the reef coral Fungia granulosa Kluzinger, 1879 at Eilat, northern Red Sea. J Exp Mar Biol Ecol 249:199-218

Crabbe MJC, Smith DJ (2005) Sediment impacts on growth rates of Acropora and Porites corals from fringing reefs in Sulawesi, Indonesia. Coral Reefs 24:437-441

Ebert TA (1999) Plant and animal populations: methods in demography. Academic Press, New York

Epstein N, Bak RPM, Rinkevich B (1999) Implementation of a small-scale 'no-use zone' policy in a reef ecosystem: Eilat's reef-lagoon six years later. Coral Reefs 18:327-332

Glassom D, Chadwick NE (2006) Recruitment, growth and mortality of juvenile corals at Eilat, northern Red Sea. Mar Ecol Prog Ser 318:111-122

Glassom D, Zakai D, Chadwick-Furman NE (2004) Coral recruitment: a spatio-temporal analysis along the coastline of Eilat, northern Red Sea. Mar Biol 144:641-651

Goffredo S, Chadwick-Furman NE (2003) Comparative demography of mushroom corals (Scleratinia: Fungiidae) at Eilat, northern Red Sea. Mar Biol 142:411-418

Goffredo S, Mattioli G, Zaccanti F (2004) Growth and population dynamics model of the Mediterranean solitary coral Balanophyllia europaea (Scleractinia, Dendrophylliidae). Coral Reefs 23:433-443

Grigg RW (1974) Growth rings: annual periodicity in two gorgonian corals. Ecology 55:876-881

Grigg RW (1975) Age structure of a longevous coral: a relative index of habitat suitability and stability. Am Nat 109: 647-657

Editorial responsibility: Howard Browman (Associate Editorin-Chief), Storebø, Norway
Grigg RW (1984) Resource management of precious corals: a review and application to shallow water reef building corals. PSZN I: Mar Ecol 5:57-74

Harriott VJ, Banks SA (1995) Recruitment of scleractinian corals in the Solitary-Islands-Marine-Reserve, a highlatitude coral-dominated community in eastern Australia. Mar Ecol Prog Ser 123:155-161

Hughes TP (1984) Population dynamics based on individual size rather than age: a general model with a reef coral example. Am Nat 123:778-795

Hughes TP, Connell JH (1987) Population dynamics based on size or age - a reef coral analysis. Am Nat 129:818-829

Hughes TP, Jackson JBC (1980) Do corals lie about their age? Some demographic consequences of partial mortality, fission, and fusion. Science 209:713-715

Hughes TP, Jackson JBC (1985) Population dynamics and life histories of foliaceous corals. Ecol Monogr 55: 141-166

Hughes TP, Tanner JE (2000) Recruitment failure, life histories, and long-term decline of Caribbean corals. Ecology 81:2250-2263

Jokiel PL, Maragos JE, Franzisket L (1978) Coral growth: buoyant weight technique. In: Stoddart DR, Johannes RE (eds) Coral reefs: research methods. UNESCO, Paris, p 529-541

Kaufmann KW (1981) Fitting and using growth curves. Oecologia 49:293-299

Loya Y (1972) Community structure and species diversity of hermatypic corals at Eilat, Red Sea. Mar Biol 13:100-123

Loya Y (1976) The Red Sea coral Stylophora pistillata is an r strategist. Nature 259:478-480

Loya Y (2004) The coral reef of Eilat-past, present and future: three decades of coral community structure studies. In: Rosenberg E, Loya Y (eds) Coral health and disease. Springer-Verlag, Berlin, p 1-34

Loya Y, Slobodkin LB (1971) The coral reefs of Eilat (Gulf of Eilat, Red Sea). Symp Zool Soc Lond 28:117-139

Rinkevich B, Loya Y (1986) Senescene and dying signals in a reef building coral. Experientia 42:320-322

Rinkevich B, Frank U, Bak RPM, Muller WEG (1994) Alloimmune responses between Acropora hemprichii conspecifics: nontransitive patterns of overgrowth and delayed cytotoxicity. Mar Biol 118:731-737

Ross MA (1984) A quantitative study of the stony coral fishery in Cebu, Philippines. PSZN I: Mar Ecol 5:75-91

Sheppard CRC, Sheppard ALS (1991) Corals and coral communities of Arabia. Fauna Saudi Arabia 12:1-170

Smith LD, Devlin M, Haynes D, Gilmour JP (2005) A demographic approach to monitoring the health of coral reefs. Mar Pollut Bull 51:399-407

Vermeij MJA, Bak RPM (2000) Inferring demographic processes from population size structure in corals. In: Proc 9th Int Coral Reef Symp, Vol 1. International Coral Reef Society, Bali, p 589-593

Veron JEN (2000) Corals of the World, Vol 1. Australian Institute of Marine Science, Townsville

Yap HT, Alino PM, Gomez ED (1992) Trends in growth and mortality of three coral species (Anthozoa: Scleractinia), including effects of transplantation. Mar Ecol Prog Ser 83: 91-101

Zakai D, Chadwick-Furman NE (2002) Impacts of intensive recreational diving on reef corals at Eilat, northern Red Sea. Biol Conserv 105:179-187

Zakai D, Dubinsky Z, Avishai A, Caaras T, Chadwick NE (2006) Lunar periodicity of planula release in the reefbuilding coral Stylophora pistillata. Mar Ecol Prog Ser 311: 93-102

Submitted: November 21, 2005; Accepted: August 17, 2006

Proofs received from author(s): February 28, 2007 